\title{
Network Modeling of EOR Processes: A Combined Invasion Percolation and Dynamic Model for Mobilization of Trapped Oil
}

\author{
S. F. Bolandtaba - A. Skauge
}

Received: 6 April 2010 / Accepted: 30 April 2011 / Published online: 19 May 2011

(C) The Author(s) 2011. This article is published with open access at Springerlink.com

\begin{abstract}
A novel concept for modeling pore-scale phenomena included in several enhanced oil recovery (EOR) methods is presented. The approach combines a quasi-static invasion percolation model with a single-phase dynamic transport model in order to integrate mechanistic chemical oil mobilization methods. A framework is proposed that incorporates mobilization of capillary trapped oil. We show how double displacement of reservoir fluids can contribute to mobilize oil that are capillary trapped after waterflooding. In particular, we elaborate how the physics of colloidal dispersion gels (CDG) or linked polymer solutions (LPS) is implemented. The linked polymer solutions consist of low concentration partially hydrolyzed polyacrylamide polymer crosslinked with aluminum citrate. Laboratory core floods have shown demonstrated increased oil recovery by injection of linked polymer solution systems. LPS consist of roughly spherical particles with sizes in the nanometer range $(50-150 \mathrm{~nm})$. The LPS process involve mechanisms such as change in rheological properties effect, adsorption and entrapment processes that can lead to a microscopic diversion and mobilization of waterflood trapped oil. The purpose is to model the physical processes occurring on pore scale during injection of linked polymer solutions. A sensitivity study has also been performed on trapped oil saturation with respect to wettability status to analyze the efficiency of LPS on different wettability conditions. The network modeling results suggest that weakly wet reservoirs are more suitable candidates for performing linked polymer solution injection.
\end{abstract}

Keywords Network model · Trapped oil mobilization · EOR processes · Linked polymer solution · Colloidal dispersion gel

S. F. Bolandtaba $(\bowtie) \cdot$ A. Skauge Center for Integrated Petroleum Research (CIPR), Allegaten 41, 5007 Bergen, Norway e-mail: Saeed.Fallah@cipr.uib.no

A. Skauge

e-mail: Arne.Skauge@cipr.uib.no 


\section{List of Symbols}

$\begin{array}{ll}A & \text { Langmuir adsorption coefficient }\left(\mathrm{cm}^{3} / \mathrm{g}\right) \\ A P_{1,2,3} & \text { Constant coefficients }\left(\mathrm{cm}^{3} / \mathrm{g}\right) \\ B & \text { Langmuir adsorption coefficient }\left(\mathrm{cm}^{3} / \mathrm{g}\right) \\ C_{\mathrm{lg}} & \text { Critical concentration for } \log \text { jamming mechanism }\left(\mathrm{g} / \mathrm{cm}^{3}\right) \\ C_{\mathrm{p}} & \text { Polymer concentration }\left(\mathrm{g} / \mathrm{cm}^{3}\right) \\ C_{\mathrm{s}} & \text { Critical concentration for straining mechanism }\left(\mathrm{g} / \mathrm{cm}^{3}\right) \\ f & \text { Fractional flow rate }(-) \\ G & \text { Absolute pore element conductance } \\ G_{\mathrm{f}} & \text { Water corner layer conductance } \\ g_{\mathrm{pc}} & \text { Bonds conductance } \\ G_{\mathrm{W}} & \text { Water bulk conductance } \\ i, j, k & \text { Bonds index }(-) \\ N_{\mathrm{ca}} & \text { Capillary number }(-) \\ P & \text { Pressure (Pa) } \\ Q & \text { Bonds flow rate (m } 3 / \mathrm{s}) \\ q & \text { Flow rate (m } 3 / \mathrm{s}) \\ R_{\mathrm{b}} & \text { Bond radius }(\mu \mathrm{m}) \\ R_{\mathrm{p}} & \text { Polymer effective hydrodynamic radius }(\mu \mathrm{m}) \\ S & \text { Log-jamming curve increase }(-) \\ \alpha & \text { Oil-filled fractional in partially filled bond } \\ \mu & \text { Viscosity (Pa.s) } \\ \mu_{\mathrm{w}} & \text { Water viscosity (Pa.s) } \\ \sigma & \text { Interfacial tension }(\mathrm{N} / \mathrm{m})\end{array}$

\section{Introduction}

Conventional oil recovery methods like water flooding may leave large amount of unswept and capillary trapped oil in the reservoir. Enhanced oil recovery methods aim to mobilize as much as possible of the oil left behind. Fluid transport in porous media is generally quite complex, but the complexity is further increased when enhanced oil recovery processes is applied. There are a number of techniques on different scales developed to increase our understanding of multiphase flow problems. These techniques include simulation of flow on small scale using pore-scale network models in which the pore space is represented by simplified geometry. Pore level network modeling provides a different approach to understand the physical processes compared to other modeling techniques. A number of numerical methods, such as includes Lattice-Boltzmann method (Gunstensen and Rothman 1993; Van Kats and Egberts 1993) has been developed which can model complex flow problems on 3D images of rock without any pore geometry idealization. Even though these methods give good local description of multiphase processes in porous media, they are computationally expensive (Porter et al. 2009). Thus, the application of Lattice-Boltzmann methods is often limited to relatively simple situations with limited number of pores (Blunt et al. 2002). Understanding of physical processes appearing during enhanced oil recovery processes can be achieved using a pore-scale network modeling approach. Network modeling has become a powerful tool in analyzing fluid flow. In particular, applications to multiphase flow problems have been studied in order to understand the physical flow mechanisms that govern the fluids transport properties in porous media. Some extensive reviews explaining 
the development of network models exist in literature (see Van Brakel 1975; Blunt et al. 2002).

Studies of polymer gel systems have become an important aspect of enhanced oil recovery methods. The possibility of increasing oil recovery by polymer gel injection has generated interest in developing modeling techniques that can be used to investigate the physical displacement mechanisms of the process. Polymer gels were first developed for water shutoff and also for in-depth sweep improvement during waterflood. One class of polymer gel systems developed specifically for in-depth sweep improvement is called colloidal dispersion gels (CDG). There are little systematic studies describing in detail the relevant mechanisms for the colloidal dispersion gel process. Most studies have focused on propagation of gel in porous medium and finding ways to delay the gelation time. The gelation behavior of colloidal dispersion gel system was studied by Ranganathan et al. (1998) and Rocha et al. (1989) with the aim to understand the performance of CDG on in-depth permeability modification. Dong et al. (1998) performed extensive displacement experiments and also studied CDG structure and rheology using atomic force microscopy (AFM) and dynamic rheological methods.

The first field applications of CDG were reported by Mack and Smith (1994) who analyzed the result from 29 field trials and concluded that about $70 \%$ of the field trials had been technically successful, showing positive results on oil production. They claimed that colloidal dispersion gels increases the oil recovery significantly, but factors like injection of CDG at higher water cut, poor well completion and water salinity may reduce the process efficiency. More recently, there have been several reports of CDG field trials (Chang et al. 2006; Dias et al. 2008) where also incremental oil recovery was observed. The conventional approach from the 1980's target mainly macroscopic sweep improvement, while the more recent CDG approach also named Linked Polymer Solution (LPS) discussed in Aarra et al. (2005), Bjørsvik et al. (2007), Bjørsvik (2008), and Spildo et al. (2008) aim at improving the microscopic displacement efficiency in addition to the macroscopic sweep.

The history of network modeling applied in the area of non-Newtonian fluid begins with the study of Savins (1969) where the relation between Darcy velocity and pressure drop for the non-Newtonian fluids was investigated in a capillary bundle model. More recently, Hou (2007) established a microscopic model for polymer flooding where various polymer mechanisms were incorporated and residual oil distribution after the polymer flooding was studied. There are now several network models developed to study the behavior of non-Newtonian fluids (Shah 1994; Valvatne et al. 2004). There are also a few numerical models established specifically for the colloidal dispersion gel systems. Examples include the model generated by Shiyi et al. (2000) to simulate polymer flooding which is also capable of representing flow in low concentration gel systems. However, these models do not show how the residual oil at the end of water flood can be mobilized during polymer gel system. Recently, we (Bolandtaba et al. 2009) proposed an algorithm to simulate flow of colloidal dispersion gel using network modeling technique. The detailed description and formulation of different polymer mechanisms (adsorption, entrapment, and viscosity effect) were explained and the most dominant polymer mechanism during CDG injection was identified. In addition, we described the concept of "microscopic diversion" caused by gradual blocking of pore-channels leads to diversion of local flow and as a consequence mobilization of trapped oil.

In this article, we propose an algorithm that has the flexibility to model several EOR processes. Based on the algorithm, we have developed a pore scale network model which is capable of investigating the movement of residual oil during most water-based EOR processes. In addition, an approach of pore scale modeling by coupling a two-phase quasi-static network model with a single-phase transport model has been developed in order to achieve better estimation of fluid flow. The methodology has been applied to study the flow of 
colloidal dispersion gel and linked polymer solution. The different mechanisms involved in LPS have been evaluated by sensitivity studies on the network model. The local oil-water distribution may influence the LPS process, and therefore, the impact of wettability is also discussed.

\section{Methodology}

\subsection{Polymer Mechanisms}

Linked polymer solutions are nano-scale polymer particles that are cross-linked with aluminum citrate at very low concentration (typically less than $600 \mu \mathrm{g} / \mathrm{g}$ ). This recovery method is applied in oil fields in order to increase the microscopic displacement efficiency and macroscopic sweep efficiency. Although the polymer concentration in LPS systems is low, and is not comparable to that of traditional polymer flooding, same polymer mechanisms could still be considered to affect porous media and fluid behavior during the LPS injection. These mechanisms include polymer adsorption, polymer entrapment processes, and effect of polymer particles on viscosity of the solution.

\subsubsection{Viscosity Effect}

Introducing high molecular weight polymer particles to the water phase increases the solution viscosity resulting in better mobility ratio and improvement of the areal sweep. Polymer solutions are non-Newtonian fluids thus unlike the typical reservoir fluids, their viscosity varies with shear rate and solvent (water) salinity. However, earlier studies of LPS; Bjørsvik (2008), have shown Newtonian behavior, we therefore have adopted Flory (1953) correlation (see Eq. 1) to calculate the change of viscosity due to the concentration variation.

$$
\mu_{\mathrm{po}}=\mu_{\mathrm{w}}\left[1+\left(A P_{1} C_{\mathrm{p}}+A P_{2} C_{\mathrm{p}}^{2}+A P_{3} C_{\mathrm{p}}^{3}\right)\right]
$$

where $\mu_{\mathrm{w}}$ is the water viscosity (Pa.s), $A P_{1,2,3}$ is the constant coefficients $\left(\mathrm{cm}^{3} / \mathrm{g}\right)$, and $C_{\mathrm{p}}$ is the polymer concentration $\left(\mathrm{g} / \mathrm{cm}^{3}\right)$.

\subsubsection{Entrapment Effects}

Blocking of narrow pore channels by polymer particles is known as polymer entrapment. The blocking could take place whether by one large polymer particle or by the slow aggregation of polymer molecules or crosslinked particles. The former process is called "Straining" while the latter is known as "log-jamming". Either of these mechanisms can improve the local sweep efficiency by diverting the flow towards upswept oil.

Many authors have addressed entrapment mechanisms in the literature (see for example Szabo 1979; Dominguez and Willhite 1977). Huh et al. (1990) described the entrapment of the polymer in pore spaces, both theoretically and experimentally, and developed an analytical solution for flow of single phase polymer solution in a core to interpret laboratory core flood data. The evidence for mechanical entrapment is either that the polymer concentration in the effluent would not reach the inlet concentration (Osterloh and Law 1998) or would do so only after injecting large volume of polymer (Sorbie 1991).

The size of particles in the linked polymer solution is very small compared to the size of pore throats. This means that the possibility of pore elements being blocked by a single 


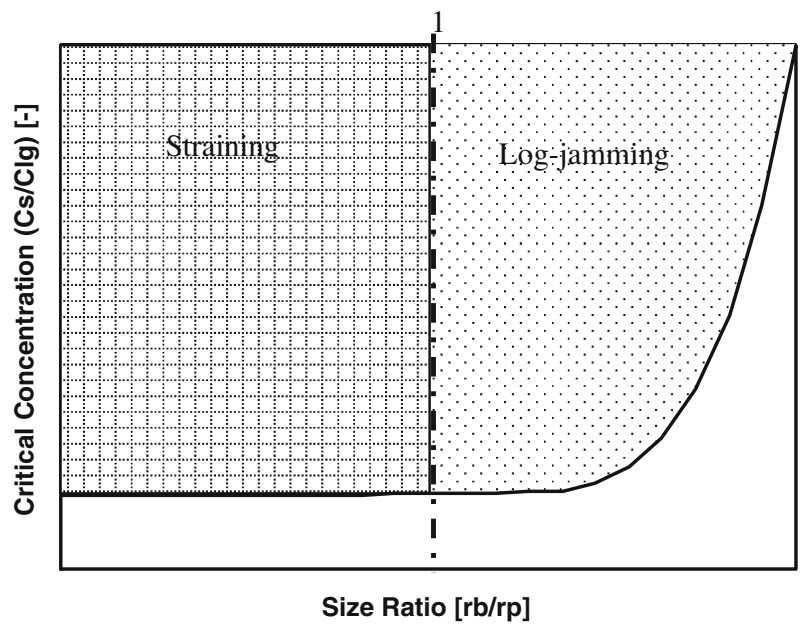

Fig. 1 The area confined by controlling parameters (i.e., size ratio, critical concentration and increase of log-jamming curve) separating the "Straining" mechanism from "Log-jamming" mechanism. $r_{\mathrm{b}}$ is the pore element size while $r_{\mathrm{p}}$ is size of the polymer particle

polymer particle (Straining mechanism) is extremely low. Since polymer particles are heavier than water, they are delayed during acceleration through pore channels. When the solution reaches a narrow pore throat, water flows faster through the restriction. This leads to an aggregation of particles at the throat inlet, which slowly narrows the entry radius of the throat and eventually prevents fluid flow through the restriction. This pore blocking mechanism is known as log-jamming.

Recently, we modeled the entrapment mechanisms by defining a number of controlling parameters (Bolandtaba et al. 2009). We used the size ratio between the polymer particle and pore element to distinguish between straining (ratio $<1$ ) and log-jamming (ratio $>1$ ) processes. We also defined the term "critical polymer concentration" which was used to determine the occurrence of pore element blocking. In concentrations higher than the critical concentration, statistically, we assume that there are enough polymer molecules in the flow required to block a certain pore channel. For the size-ratios above unity the critical concentration is not constant, hence another parameter which is called "Log-jamming curve increase" is used to capture the trend. The log-jamming curve increase is the exponent in the power-law correlation (see Eq. 2) employed to model the critical concentration as a function of the size ratio. The controlling parameters determine the dominating entrapment mechanism. This has been schematically illustrated in Fig. 1.

$$
C_{\mathrm{lg}}=C_{\mathrm{s}}\left\{\frac{e^{\left(\frac{R_{\mathrm{b}}}{R_{\mathrm{p}}}\right)^{S}}-1}{e-1}\right\}
$$

where $C_{\lg }$ is the critical concentration for $\log$ jamming mechanism $\left(\mathrm{g} / \mathrm{cm}^{3}\right), C_{\mathrm{s}}$ the critical concentration for straining mechanism $\left(\mathrm{g} / \mathrm{cm}^{3}\right), R_{\mathrm{p}}$ the polymer effective hydrodynamic radius ( $\mu \mathrm{m}), R_{\mathrm{b}}$ the bond radius $(\mu \mathrm{m})$, and $S$ is the log-jamming curve increase (-). 


\subsubsection{Adsorption Effect}

Adsorption of polymer onto the rock also reduces the conductance of the pore elements due to a decreased area open to flow. As a result, water mobility decreases and the displacement front becomes more stable. In the presented algorithm, the Langmuir adsorption isotherm has been used (see Eq. 3) to model the adsorption at different polymer concentration.

$$
C_{\mathrm{Ads}}=\frac{A C_{\mathrm{P}}}{1+B C_{\mathrm{P}}}
$$

$C_{\mathrm{P}}$ is the polymer concentration and " $A$ " and " $B$ " are constant terms which vary for different brine salinity.

\subsection{Network Model (NM)}

Injection of colloidal dispersion gels is classified as a tertiary oil recovery method. The tertiary EOR methods can be applied when the reservoir has already been flooded with water and the remaining oil is either capillary trapped or unswept by water. Gaining insight into enhanced oil recovery methods requires understanding of the fundamental physics of fluid displacement at the pore scale prior to any upscaling of macroscopic properties and flow functions. Network modeling can be employed as an investigative tool to achieve such an understanding for the EOR processes.

In the network models, the pore volume of the rock where fluids could potentially flow can be expressed as a network of interconnected nodes and bonds in which the nodes represent the pore bodies and the bonds represent the pore elements. The concept of representing the void space of rock with a network of connected pores and throats was first introduced by Fatt $(1956 a, b, c)$. He generated a regular 2D lattice with distributed pore throats radii. The pore bodies in his model had no volume. He then managed to produce the macroscopic properties such as capillary pressure and relative permeability by filling of pore throats sequentially in the order of decreased inscribed radius. Chatzis and Dullien (1977) extended the modeling approach suggested by Fatt on a 3D lattice. They maintained that the $2 \mathrm{D}$ representations of porous media are not reliable for 3D predictions of fluid flow behavior.

Percolation theory has facilitated multiphase flow modeling by the pore networks (Broadbent and Hammersley 1957; Wilkinson and Willemsen 1983; Heiba et al. 1992). Network modeling is now used to study wide range of phenomena such as simulation of drainage and imbibition processes (Singh and Mohanty 2003), the effect of wettability (Kovscek et al. 1993; Dixit et al. 1999), the effect of pore structure on relative permeability and capillary pressure (Jerauld and Salter 1990), three phase flow (Fenwick and Blunt 1998), and ganglion mobilization (Dias and Payatakes 1986a,b).

In general, the micro-scale flow modeling can be studied with two types of network models; quasi-static and dynamic models. In the former, which is the most used network model type, the effect of viscous forces on fluid displacement is neglected in both bulk fluid (fluid that fills the center of the pore-throats) and wetting layers (fluid resides in the corners of the pore-throats). Examples of these models include studies performed by Jerauld and Salter (1990); Blunt et al. (1992), Øren et al. (1998), Valvatne and Blunt (2004), and Ryazanov et al. (2009).

In the quasi-static models, a fixed capillary pressure is imposed on all the network elements in several small steps and equilibrium state of each fluid-fluid interface is interrogated by a stability test which relates the capillary pressure to the interfacial tension, contact angle and the pore space geometry. At each capillary step, the fluid configurations in the 
elements are changed based on the stability criteria. An unstable interface moves through the network until either it meets the outlet boundary of the network or it reaches another stable position. Displacement happens only if the fluid to be displaced has outlet connectivity. Note that quasi-static models simulate multiphase flow at equilibrium state without computing the pressure field throughout the network. Extensive literature reviews about these models have been given by Sahimi (1995), Berkowits and Balberg (1993), and Heiba et al. (1992).

In the dynamic network models, fluid displacement is controlled by both viscous and capillary forces. Thus, the dynamic model provides a rate-dependent displacement approach for simulating multiphase flow in porous media. Koplik and Lasseter (1985) used a dynamic model to simulate the imbibition process in a 2D network. In their simulations they neglected the flow through the wetting layers and assumed that displacement occurs only in the bulk section of pore elements. Payatakes and co-workers (Dias and Payatakes 1986a,b) developed a dynamic model to investigate the mobilization of disconnected oil (oil ganglia). Van der Marck et al. (1997) used a dynamic model for simulating drainage flow. They compared the results from the model with micro model experiments and found good agreement except for high rate and high viscosity flow. Several other authors have used dynamic models for many applications such as simulating drainage (Al-Gharbi and Blunt 2005), modeling the imbibition process (Mogensen and Stenby 1998), fingering in fractured porous media (Hughes and Blunt 2001), and matching experimental data (Van der Marck et al. 1997; Constantinides and Payatakes 1996; Avraam and Payatakes 1999).

The capillary- and viscous-dominating processes can be distinguished by the capillary number (see Eq. 4). The capillary number is the ratio of viscous to capillary forces, and is mostly used to relate changes in the residual oil saturation as a function of increase in the capillary number.

$$
N_{\mathrm{ca}}=\frac{\mu \nu}{\sigma}
$$

where $N_{\mathrm{ca}}$ is the capillary number (-), $\mu$ the viscosity (Pa.s), $v$ the velocity $(\mathrm{m} / \mathrm{s})$, and $\sigma$ is the interfacial tension $(\mathrm{N} / \mathrm{m})$.

Neglecting viscous forces for low capillary numbers (typically $10^{-6}$ ) in the bulk fluid is a reasonable assumption. However, small changes in conductivity of wetting layers due to the rate effect at such low capillary number can result in significant change on fluid displacement, residual oil and transport properties. Dynamic models consider this rate dependent effect but still they can not provide a full treatment of the problem. As mentioned earlier, many authors used dynamic modeling approach to simulate drainage, imbibition and even mobilization of trapped oil in porous media. However, in these models, the pressure field is computed by simplifying assumptions regarding the film flow and swelling of wetting layer (Nguyen et al. 2004). Unlike quasi-static models, the pressure is calculated by applying mass balance for all phases assuming that all the fluid interfaces are potentially mobile. Instead of computing pressure for all the phases, only pressure in the water is calculated and pressure for other phases is found from the local capillary pressure (Blunt et al. 2002). The other disadvantage of the dynamic models is that solving the pressure field requires several iterations for each element filled (pores and throats) even for the drainage process. The whole simulation is very time-consuming and needs several assumptions and approximations being considered (Blunt et al. 2002).

All pore network models currently available have limitations in the ability to capture the physics of fluids displacement in porous media. This is even more amplified when modeling of enhanced oil recovery techniques are needed. Modeling of EOR methods requires more detailed deterministic models to describe the physical flow mechanisms and provide 
appropriate estimation of transport properties. The approach discussed here is an attempt aimed at handling EOR processes on the pore scale.

\subsection{LPS Modeling Procedure}

In order to model colloidal dispersion gel flow and understand the physics of the process, a physically based model is required that can simulate both viscous and capillary force-related displacements. This can be achieved if a combination of quasi-static and dynamic network models is incorporated. However, constructing a convenient procedure for combining the two pore-scale simulators is a challenging task.

A novel algorithm is used to study the effect of linked polymer solutions on fluid transport properties and mobilization of residual oil. The algorithm involves combining a two-phase quasi-static network model with a single-phase transport model. The quasi-static model is used for investigating fluid flow during primary drainage, ageing and water imbibition, while the latter is used to simulate the frontal advance of LPS and to determine effects of the physical mechanisms imposed by LPS. Mobilization of disconnected oil phase in network modeling context has been discussed by several authors (Payatakes 1982; Dias and Payatakes 1986a; Joekar-niasar et al. 2010). The technique they present involves consideration of both viscous and capillary forces to displace the capillary trapped phase. Similar to the previous studies, in our algorithm, the interplay between these two forces determines the possibility of mobilizing trapped oil. The algorithm allows us to evaluate the efficiency of LPS injection on reducing the residual oil saturation and determine the change in transport properties due to several different LPS mechanisms.

For quasi-static calculation, we used the previously developed network model by Ryazanov et al. (2009). In their model, the cross-sections of pore elements are modeled as circles, arbitrary triangles and star shapes. Representing the pore elements with circular cross-sections does not allow us to include wetting layers. Therefore, in the model we developed, all the bonds can have any angular shapes, but circular. The angular shape of pore-throats allows the occurrence of wetting layers. Furthermore, nodes are assigned to contain no volume and all the volume are distributed in the bonds.

The whole simulation process begins with primary drainage and continues by ageing or changing wettability in the oil-filled pores and thereafter water injection until the oil phase is fully trapped at all positions in the network. All the calculations up to this point are performed in the quasi-static network. The process continues by extracting the water-filled elements from the two-phase network. We have named this single-phase network the "Water Backbone", and we use it to perform time-dependent (dynamic) calculations and model displacements that happen during the LPS injection. These dynamic calculations specify how fluid and rock properties change due to the several mechanisms imposed by the linked polymer solution. The change in rock and fluid properties affects the water backbone and generates a new pressure field, which in turn can increase the local pressure drop in the pore elements and lead to the oil mobilization. Figure 2 shows the flow chart of the whole simulation. In the following section, detailed explanation of each step in the modeling is elaborated.

\subsubsection{Quasi static Processes}

2.3.1.1. Primary Drainage Initially, we assume the network is fully saturated with water and all the bonds are water wet, having the distributed contact angle of $\theta_{\mathrm{pd}}$. Given the bond's radius, contact angle, and interfacial tension, the entry pressure for each bond is calculated. Primary drainage is simulated by changing capillary pressure in a number of small steps in 


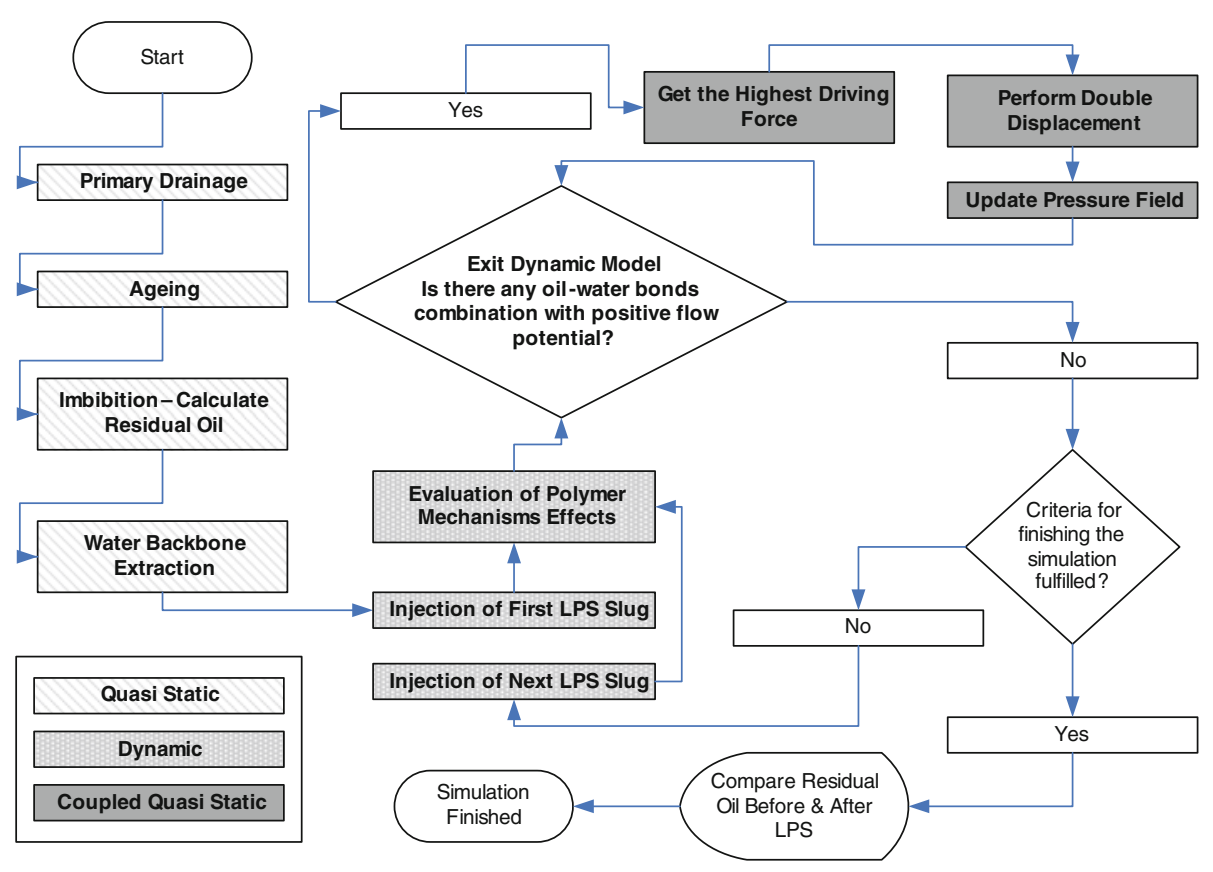

Fig. 2 The flow chart showing LPS simulation steps. The processes in each network type (quasi-static, dynamic and coupled quasi-static) have been shown by different patterns (pattern map in bottom left)

the network model. At each step, the increase in oil-water capillary pressure is followed by examining interface stability using the Young-Laplace equation. Those interfaces which are unstable, as a result, change their configurations to equilibrium values. It should be noted that oil invades the water bonds which are accessible and have phase continuity towards the network outlet. This mechanism that is known as piston-like displacement is the only displacement mechanism during the primary drainage. Water bonds are invaded by oil in the order of their entry pressure which means that those with lower entry pressures are invaded first. The primary drainage process, simulated in this way is similar to the bond invasionpercolation process (Wilkinson and Willemsen 1983).

Primary drainage displacements end at connate water saturation, where all the water-filled elements are outlet-disconnected. At this point, the volume of water trapped in pore channels and the volume of water corner layers in oil bonds give the irreducible water saturation.

2.3.1.2. Ageing The primary drainage is followed by a possible change in wettability in the oil-filled pores (ageing process). Nevertheless, water layers sitting in the corner of the channels remain water wet. In this article, we have included the possibility of choosing among following wettability classes (Skauge and Ottesen 2002); Mixed wet large, mixed wet small and fractional wet (See Table 1).

The ageing process is simply modeled by assigning different intrinsic contact angles in the pore elements that have been invaded by oil during primary drainage. Due to the surface roughness of the rock, the contact angles may not be the same for the different flow directions. This implies that the advancing and receding contact angle distribution, that correspond to water and oil invasion, respectively, may differ from intrinsic contact angles measured on 
Table 1 Three wettability classes which can be used in the model for simulation of ageing process

\begin{tabular}{ll}
\hline Wettability class & Description \\
\hline Mixed wet large (MWL) & Large pores are oil wet \\
Mixed wet small (MWS) & Small pores are oil wet \\
Fractional wet (FW) & Oil wet pores are distributed randomly \\
\hline
\end{tabular}

a smooth surface. A relationship between advancing/receding contact angles and the intrinsic contact angles has been given by Morrow (1975). By defining a distribution of intrinsic contact angles, the receding and advancing contact angles can be calculated using this relationship.

2.3.1.3. Imbibition Water injection is the next step after the wettability alteration. Due to presence of water corner layers and the wettability change during the ageing, the imbibition process is more complicated than the drainage (Patzek 1998). In this article, detailed theoretical aspects of imbibition will not be discussed. Various displacement schemes which occur during water imbibition have been investigated by Lenormand and Zarcone (1984) and also by Mohanty and Salter (1982).

During imbibition, the fluid configuration at the pore level is controlled by two distinct mechanisms; piston-like displacement (Lenormand and Zarcone 1984) and snap-off (Patzek 1998). The piston-like displacement of oil by water is similar to that of the drainage process. In the snap-off mechanism, however, water invades an oil-filled element that has no adjacent element filled with water in their bulk sections. The swelling of water resided in the corners, displaces oil in the snap-off process. The competition between piston-like and snap-off events for pore filling is closely related to several factors including pore size distribution, pore geometry, wettability, and connectivity of the network. Snap-off is also a function of capillary number and viscosity ratio and can be suppressed by large capillary number and in stable invasions. The effect of flow rate on snap-off during the imbibition process has been studied by Nguyen et al. (2004). In our model, the dynamic effects on snap-off have been ignored and snap-off is only a function of geometry and topology of pore elements. Snap-off is the main mechanism responsible for the generation of disconnected oil phase.

The displacement of oil by water still follows the general rules of the quasi-static approach. This implies that apart from the stability test, fluid displacement happens if the water phase is accessible to the oil-filled elements. The other displacement requirement is that the oil phase must have a continuous path until the network outlet. Water invasion stops if none of the pore elements can meet these conditions. The oil saturation at this point gives the residual oil saturation.

2.3.1.4. Water Backbone Extraction It is necessary to calculate the concentration of LPS in order to evaluate the effect of different polymer properties. LPS concentration at any distance from the injector depends on the rate of injection and therefore is a time dependent parameter. As a result, modeling approaches such as the quasi-static can not be employed to simulate the dynamic concentration variations. We consider LPS as a component in the water solution, thus its pressure is accordingly represented by the water pressure. The other assumption we make is that LPS particles travel in the bulk section of the pore elements and not in the water corner layers. Therefore, extending the flow simulation to model linked polymer solution propagation requires a single-phase transport model. Such a model is generated by 

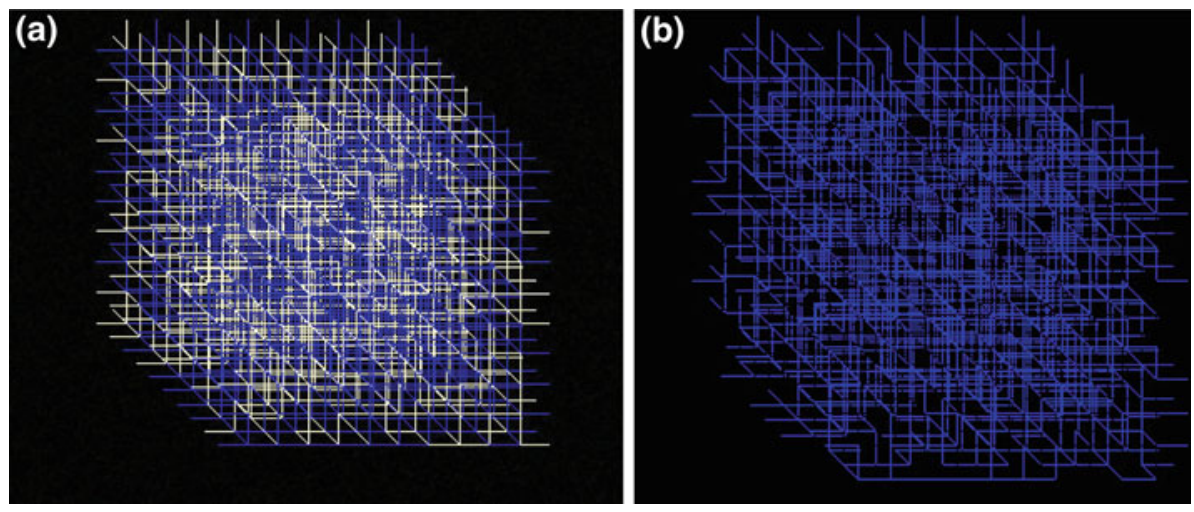

Fig. 3 a The two-phase network model at the end of imbibition. White lines represent the oil bonds while the blue lines represent the water bonds. $\mathbf{b}$ The corresponding one-phase extracted water backbone

extracting water bonds from the quasi-static network when the oil is at waterflood residual saturation.

It is important to note that trapped water bonds which have no links with the other waterfilled elements, and the oil bonds, are not included in the dynamic model. An example of the extracted network called water backbone is shown in Fig. 3. Figure 3a shows a two-phase network model at the end of the imbibition process while Fig. $3 \mathrm{~b}$ illustrates its extracted water backbone.

The pressure field of the single-phase water backbone is computed with the similar method used in the quasi-static approach to calculate the relative permeability. The oil and water are generally assumed to be incompressible. Hence the volumetric flow rate of each body can be described by the mass conservation to calculate the pressure field of the network at each phase "p" (Blunt et al. 2002) (see Eq. 5)

$$
\sum_{k} Q_{\mathrm{p}^{k}}^{i}=0
$$

(all elements $k$ connected to pore $i$ )

The flow rate for each pore element is given by:

$$
Q_{\mathrm{p}^{k}}^{i}=g_{\mathrm{pc}}\left(P_{j}-P_{i}\right)
$$

where the pore element " $k$ " connects the pores $i$ and $j . \mathrm{g}_{\mathrm{pc}}$ is the conductance of the bond.

Applying Eq. 5 and Eq. 6 for all the pore bodies generates series of equations where the nodal pressures are unknown. This set of equations can be solved by standard matrix inversion techniques to deliver the pressure at each node. Note that, the pressure field is solved only for the water phase.

\subsubsection{Dynamic Processes}

The dynamic phase of the simulation involves no oil displacement and all the computations during this phase are conducted in the water backbone network. To assess the effect of LPS mechanisms, the concentration of particles in the pore channels is the key factor which should be known. In order to calculate the particle concentration, we consider the convection principles which relate the movement of LPS in porous media. Figure 4 illustrates two pore bodies 
Fig. 4 The pore element with polymer concentration of " $C$ " connects two pore bodies having different concentrations of $C_{1}$ and $C_{2}$. The concentration of pore element changes due to the diffusion caused by different concentration of pore-bodies

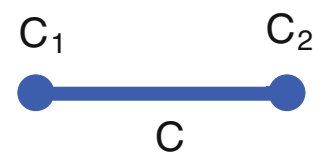

(nodes) which are connected to each other with a pore element (bond). The convection caused by the concentration difference between the two pore bodies changes the concentration of LPS inside the pore element. At each time step, the pressure and consequently the flow rate in each element is calculated and the concentration of network elements is then estimated. Mass conservation has been used to compute the concentration of LPS in the pore elements. As Eq. 7 shows, the concentration of each pore body is represented by a sum of the product of connecting pore elements concentration and their relative flow rate.

$$
C_{\text {In }}=\sum_{i=1}^{N} f_{i} * C_{i}
$$

where $\mathrm{f}_{i}$, the relative rate is given by:

$$
f_{i}=\frac{Q_{i}}{\sum_{j=1}^{N} Q_{j}}
$$

where $f$ is the fractional flow rate $(-), Q$ the flow rate $\left(\mathrm{m}^{3} / \mathrm{s}\right), C_{\mathrm{i}}$ the concentration of polymer in bond $i\left(\mathrm{~kg} / \mathrm{m}^{3}\right), C_{\text {In }}$ concentration of polymer in inlet node $\left(\mathrm{kg} / \mathrm{m}^{3}\right), i, j$ the index of connected bond to the inlet node, and $N$ is the number of bonds connected to node $i$.

The LPS concentration at the outlet of the pore element $\left(C_{\text {out }}\right)$ in next time step is simply equivalent to its concentration inside the pore element at previous time step. The bond's concentration is updated according to Eq. 9.

$$
C_{\text {new }}=C_{\text {old }}+\frac{\Delta t \cdot Q}{V}\left(C_{\text {in }}-C_{\text {out }}\right)
$$

where $\Delta t$ is the time step, $V$ is the dynamic volume of the bond, $C_{\text {in }}$ and $C_{\text {out }}$ are the inlet and outlet concentrations, respectively. We choose the time step such that only one pore element is being flooded by polymer at a time. This implies that the bond which has the lowest value of volume to flow rate is filled first.

The influence of each LPS mechanism can individually be evaluated by the reduction in water relative permeability. LPS is injected into the water backbone in several small slugs. The effect of EOR mechanisms on the pore space topology and geometry and also on the fluid properties can be investigated in the single-phase transport model or the water backbone. At each time step, the concentration of LPS particles in the pore elements is computed. Viscosity of the LPS solution in each pore element is updated using Flory equation (Eq. 1). The increase in polymer viscosity affects water conductance and consequently the pressure calculation on the network. The other physical process during LPS injection is adsorption of polymer onto the wall of the pore elements. Polymer adsorption decreases the water conductivity by reducing the hydraulic radius of the pore channels. This also influences the pressure field of the model. The possibility of pore channels become blocked by the polymer particles is important and must be investigated. If the pore element radius is smaller than the average polymer particle size and the concentration of polymer reaches the critical concentration, the 
pore channel is blocked due to the straining mechanism. On the other hand, if the size ratio is larger than one, then the critical concentration is calculated using Eq. 2 and is compared to the concentration of the pore element. If the concentration is higher than the critical concentration, the pore channel is blocked and flow through the channel ceases. This is known as the log-jamming mechanism. Either of the blocking mechanisms causes flow diversion and changes the pressure field within the network. The mechanisms of LPS affect the network topology by reducing the area open for flow (adsorption) and by preventing flow through the blocked pore channels (entrapment mechanisms). In addition, the increase in viscosity due to the polymer particle changes fluid properties and consequently the conductivity of pore elements for the water phase.

The throughput of LPS is calculated in terms of pore volume (PV) injected for each injection sequence. At each time step, the injected fraction of PV is compared to the predetermined slug volume. If PV injected exceeds this predetermined value, the LPS dynamic simulation terminates and the simulation continues to the next stage to check if any oil mobilization can be observed.

\subsubsection{Coupled Quasi Static Model}

The oil displacement in a reservoir is mainly controlled by viscous and capillary forces. In order to mobilize the capillary trapped oil, the capillary forces must decrease or viscous forces increase. The microscopic flow diversion caused by the log-jamming mechanism has been identified to play a dominant role on recovering the capillary trapped oil during the injection of LPS (Spildo et al. 2008). The LPS entrapment mechanisms change the local force balance that, in turn, can lead to the oil mobilization. Modeling approaches have been developed for displacement of disconnected oil using dynamic network models. These approaches suggest including both viscous and capillary forces as driving forces to mobilize the trapped oil. In this study, we have adopted a similar approach by considering a double displacement of the fluids consisting of displacement of oil by water (imbibition) and water by oil (drainage) for each trapped pore element that contains oil. The volume of oil displaced is determined by volume conservation.

2.3.3.1. Backbone Attachment During dynamic simulation, the conductance of the pore channels is affected by various LPS mechanisms that cause the modified backbone configuration to be different from its original state (at the end of imbibition). To evaluate the effect of LPS on reducing residual oil saturation, we substitute the latter network by the former in the two-phase quasi-static model. The new two-phase network, made by attaching the modified water backbone to the network of disconnected oil clusters gives a different pressure distribution. Such difference is used to develop criteria for trapped oil mobilization. It should be noted that once we are back to the quasi-static network, no further LPS injection is carried out; as a result no change in the conductance of the pore elements and viscosity of fluids is expected.

The fluid-fluid interface stability should be checked to determine the possibility of trapped oil mobilization. No oil displacement takes place if the same principles of quasi-static networks are applied. The reason lies in the fact that the oil clusters are still disconnected and not attached to the outlet. However, the different pressure distribution within the modified quasi-static network changes the local viscous force in each pore element. This pressure difference could contribute to the oil movement if it is larger than the local capillary pressure difference across the trapped oil. Figure 5 illustrates a disconnected oil bond that is trapped between two water pore channels. $P_{1}$ and $P_{2}$ are the water pressure at the nodes. It can be 


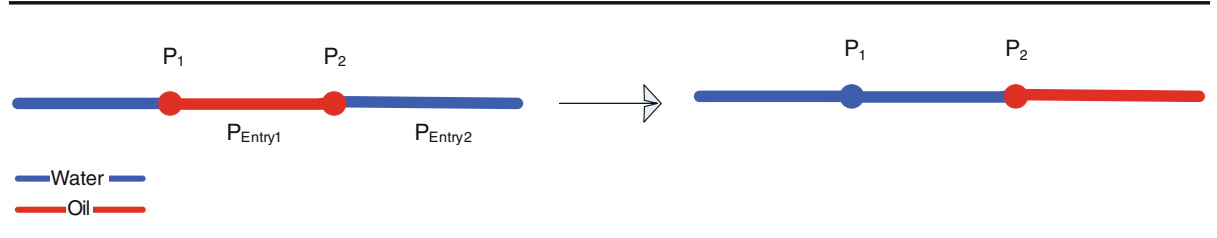

Fig. 5 The schematic of a capillary-trapped oil bond, having different nodal pressures and showing oil mobilization. $P_{\text {Entry } 1}$ and $P_{\text {Entry } 2}$ are capillary entry pressures for oil bond and water bond, respectively

shown that trapped oil in this case can be mobilized if the contribution of both viscous and capillary force could meet the following condition.

$$
P_{1}-P_{2}+P_{\text {Entry1 }}-P_{\text {Entry } 2}>0
$$

$P_{\text {Entry1 }}$ and $P_{\text {Entry2 }}$ are the water and oil bond capillary entry pressures, respectively. The left hand-side of the equation can be considered as driving force or flow potential needed to displace the oil. With respect to this method, the oil displacement consists of two movements; water displacing oil and then oil displacing water. This is a double displacement scheme that combines the drainage and imbibition processes. Note that the volume of water displaced by oil during the second part of the double displacement is produced from the outlet since the water phase is always spanning throughout the network.

The post-LPS injection simulation involves examining all the disconnected oil bonds for stability condition given by Eq. 10. As Fig. 6 illustrates, a trapped oil bond could be either a single bond or it could be part of a disconnected oil cluster. Therefore, except for water bonds linked to the higher pressure node $\left(P_{1}\right)$, all the water bonds connected to a single oil bond (Fig. 6a) or connected to an oil cluster (Fig. 6b) are tested for double displacement possibility. The flow potentials are collected for any possible combination in the network and sorted in descending order. Finally, oil is mobilized from the oil-water bonds combination that has the largest driving force. Since fluid configurations are changed due to the oil displacement, the nodal pressures are updated accordingly. This is done with the same method that is used to compute the pressure field in the quasi-static model, i.e., mass conservation. Since pressure field changes, the list of the double displacement events and their driving forces must be updated. Same procedure is repeated in order to obtain the next event having highest flow potential. The process continues until none of the possible oil-water combinations gives a positive driving force. The oil saturation at this point determines how efficient the LPS slug is to mobilize the residual oil. It should be noted that during the LPS injection, the pressure difference $(\Delta P)$ imposed between boundaries of the network is increased due to the blocking of pore channels by the entrapment mechanism. Moreover, with the given network and fluid properties at the end of the imbibition process (lower $\Delta P$ across the network) no further oil production occurs if we use the new displacement criteria (Eq. 10) and continue water flooding instead of performing LPS injection.

The volume of pore channels that accommodates the fluid is divided into two sections; bulk and corner layers. We assume that at post-LPS simulation, oil always occupies the bulk section of the pore elements while water fills both bulk and corner layer areas. The radii of pore channels are not the same, but distributed causing a variation in the volume of pore channels. Therefore, the difference between the volume of trapped oil and the volume of water bond that receives the oil during the mobilization should be considered by respecting the volume conservation. The volume conservation determines the volume of oil that should be mobilized at each mobilization event. 
(a)

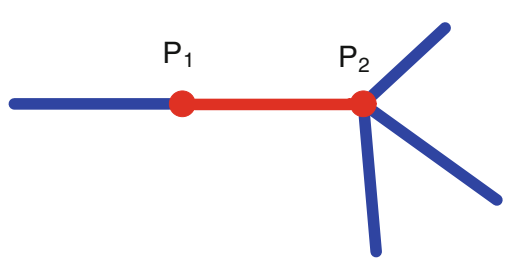

(b)

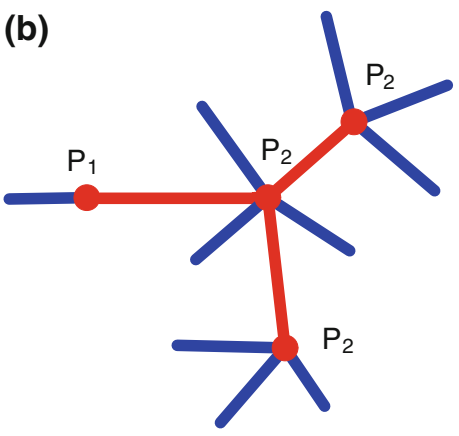

Fig. 6 The configuration of trapped oil bond(s) which could exist in network model at the end of imbibition. a The trapped oil bond is not connected to other trapped oil bonds. b A number of oil bonds connected to each other forming a trapped oil cluster. Injecting water tries to displace oil from node marked with the pressure of $P_{1}$. The displacement criterion determines the node $\left(P_{2}\right)$ from which oil displaces water
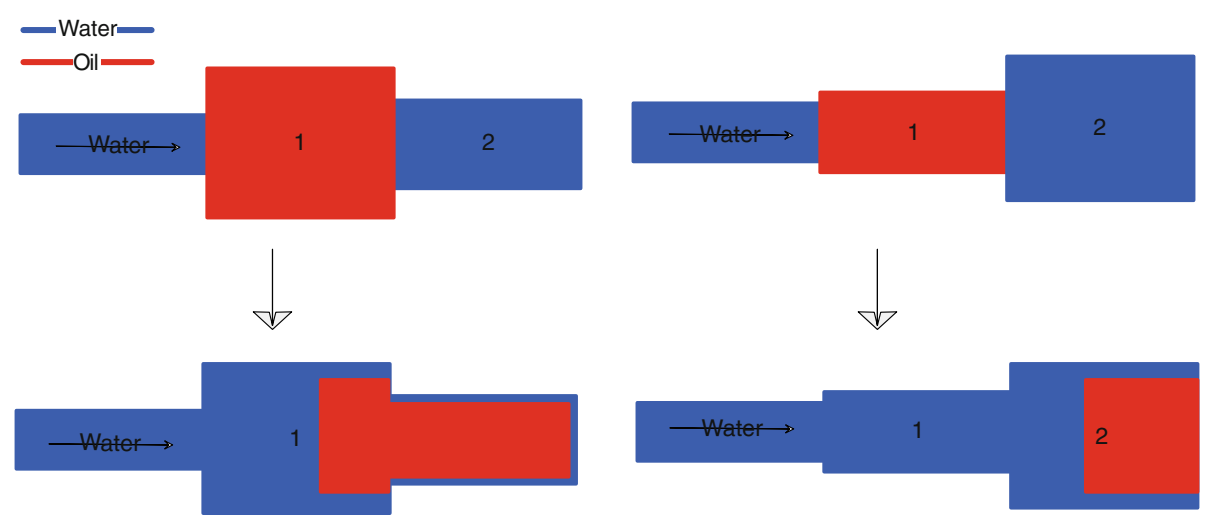

Fig. 7 Two possible double displacement where fluid configurations are shown before and after LPS injection; a The water bond (bond 2) is smaller than oil bond (bond 1) causing partial oil displacement. b The water bond is larger than oil bond leading to fully displacement of trapped oil

Figure 7 shows two mobilization scenarios where the volumes of oil and water bonds are not the same. In scenario (Fig. 7a), the water bond (bond 2) is smaller than the oil bond (bond 1) hence, only the fraction of oil volume which is equal to the bulk volume of the water bond could fill the water bond. The oil mobilization in this case causes the trapped oil being extended to the water-filled pore element. The volume of oil mobilized is replaced with the identical volume of water.

The second scenario (Fig. 7b) deals with the opposite configuration where the bulk volume of the water bond is big enough for the trapped oil to occupy the whole volume. In this case, the trapped oil is completely displaced to the water bond. In addition, the former oil bond now becomes fully filled with the water. Either configurations lead to the mobilization of the trapped oil. Oil leaves the network if it is connected to the outlet and the condition given by Eq. 10 is fulfilled.

After each displacement event, it is necessary to update water pressure in the nodes and obtain the corresponding flow rates for each pore element. This is done to compute the new list of double displacement events in order to determine what event occurs next. The pressure calculation procedure highly depends on the conductance of pore elements and the phase 
continuity. The configuration of fluid shown in Fig. 7 has been considered for calculating phase conductance after the displacement. According to this approach, in partially filled oil bond, oil occupies only a fraction of the bulk section, leaving the rest for the water phase. True conductance of the water phase is then calculated based on the water occupancy in both corner layer and bulk section. Equation 11 gives the formulation to find this fraction.

$$
\alpha=\frac{V_{\mathrm{w}}-L * A_{\mathrm{f}}}{V-L * A_{\mathrm{f}}}
$$

where $\alpha$ is the fraction, $V$ is the volume of the pore element, $V_{\mathrm{w}}$ is volume of water in the pore element, $L$ is the length of the pore element and finally $A_{\mathrm{f}}$ is the area of corner layer filled by water. The water conductance is now updated by harmonic average of corner layer and bulk conductance:

$$
\frac{1}{G_{\mathrm{w}}}=\frac{\alpha}{G}+\frac{(1-\alpha)}{G_{\mathrm{f}}}
$$

where $G_{\mathrm{w}}$ is the water bulk conductance, $G_{\mathrm{f}}$ is the water corner layer conductance, and $G$ is the absolute pore element conductance.

It should be noted that the thickness of wetting layer in the water bond where oil enters, is influenced by the shape of the pore element, the contact angle and the capillary pressure. This in turn, influences the volume of trapped oil that can be displaced to the water bond and consequently the conductivity of phases in the pore elements. Injection of following LPS slugs is carried out when no displacement with positive driving force exists. The same procedure for trapped oil mobilization is repeated after each LPS injection step. The whole simulation can reach to the end if the LPS effluent reaches stable condition and remains constant when no further blocking occurs (see Fig. 2 for the flow chart of whole process).

\section{Results and Discussion}

The flow of colloidal dispersion gel through porous media is modeled by a 3D lattice network with size of $15 \times 15 \times 15$. The simulation takes approximately $30 \mathrm{~min}$ to run on an $\operatorname{Intel}(\mathrm{R})$ Core (TM) 2 Duo CPT $(2.93 \mathrm{GHz})$ machine. The network porosity and the absolute permeability is $39 \%$ and $306.1 \mathrm{mD}$, respectively. The coordination number of a real rock sample is typically between 3 and 8 (Jerauld and Salter 1990). In this study, we chose a coordination number of 4 to construct the model. Table 2 lists the basic network properties.

In order to get consistent results with the network model, several realizations have been constructed. These realizations share the same statistical information in terms of pore size distribution, bond length, coordination number and other geometrical and topological properties. The objective is to find the minimum representative size of the model giving consistent results analogue to a representative elementary volume (REV). Several realizations of the model have been constructed. Joekar-niasar et al. (2010) determined REV by performing simulation on different network sizes using a quasi-static model and comparing the calculated capillary pressure data. Their method has been applied here in order to find the smallest network size corresponding to REV. The results are shown in Fig. 8. As can be seen from the figure, the shapes of the capillary pressure-saturation curves for networks larger than $15 \times 15 \times 15$ do not change considerably. Thus, a 3D network with 15 nodes in each direction was chosen as the base model in our study. It should be noted that these result are not representative of any experiment and mainly used to examine the algorithm. 
Table 2 Fundamental properties of the network model used in this study

\begin{tabular}{lll}
\hline Parameter & Value & Unit \\
\hline Network size & $15 \times 15 \times 15$ & Node \\
Pore size & $1-10$ & $\mu \mathrm{m}$ \\
Coordination number & 4.02 & - \\
Pore element length & 30 & $\mu \mathrm{m}$ \\
Porosity & 39 & $\%$ \\
Absolute permeability & 306.1 & $\mathrm{mD}$ \\
Interfacial tension & 41 & $\mathrm{mN} / \mathrm{m}$ \\
Initial contact angle & $0.8-1.0$ & $\mathrm{Cos}(\theta)$ \\
Wettability class (after ageing) & Mixed wet large & - \\
Oil wet contact angle (after ageing) & $(-0.2)$ to $(-0.8)$ & $\mathrm{Cos}(\theta)$ \\
Water wet contact angle (after ageing) & $0.6-0.8$ & $\mathrm{Cos}(\theta)$ \\
Largest water radius/smallest oil & & $\mu \mathrm{m}$ \\
$\quad$ radius $\left(R_{\text {wet }}\right)$ & 4 & \\
\hline
\end{tabular}

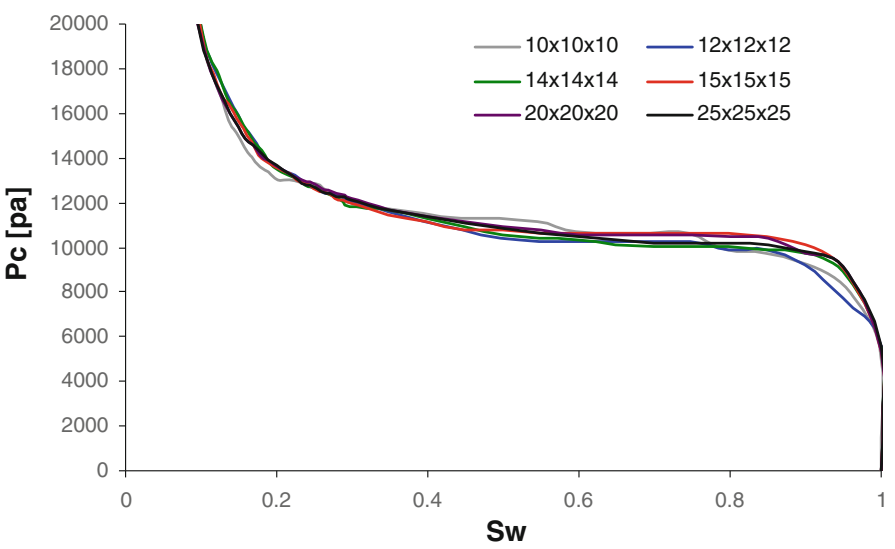

Fig. 8 Capillary pressure-saturation curve for different network size to find the smallest REV

The sequence of drainage, ageing and water imbibition is simulated and the corresponding macroscopic properties are calculated. Figs. 9 and 10 show the relative permeability and capillary pressure trend from these simulations. In fact, the drainage and following water invasion sequences are interpreted as the oil migration into the reservoir and water flooding processes, respectively. The oil phase at the end of water imbibition is outlet-disconnected and considered as the waterflood residual oil saturation.

Once we extract the water-filled elements of the network, the dynamic simulation of CDG/LPS can be started. Coupling the quasi-static and dynamic network models gives us possibility to investigate the effect of linked polymer solution on mobilizing the residual oil saturation. In line with this approach, the LPS flow characteristics and the physics of the process can be studied by analyzing different mechanisms affecting fluid/fluid and fluid/rock properties. 


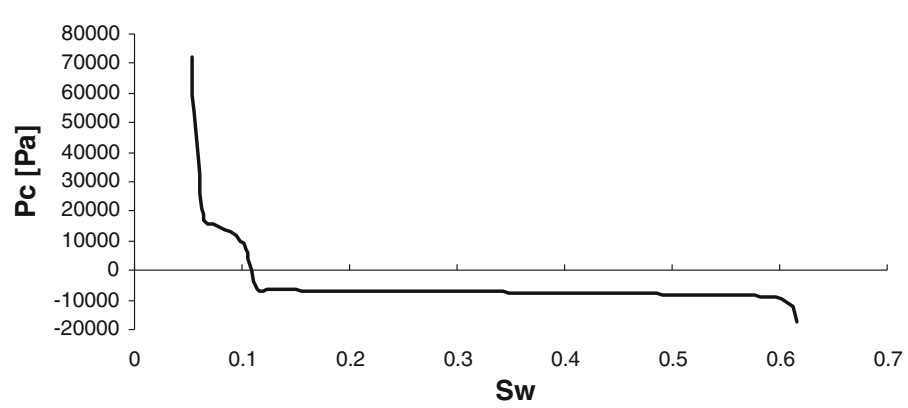

Fig. 9 The capillary pressure calculated from the network model during the imbibition process

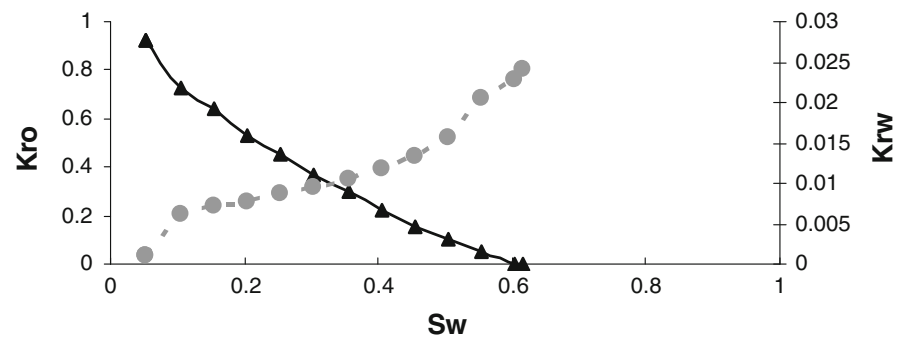

Fig. 10 Relative permeability of oil and water during imbibition process

\subsection{Microscopic Diversion}

With the aid of the displacement algorithm, we could now analyze trapped oil movement under effect of LPS flow. Figure 11 shows the ratio of residual oil saturation reduction $\left(S_{\text {or }}-S_{\text {or_Init }}\right)$ to initial residual oil saturation $\left(S_{\text {or_Init }}\right)$ as a function of pore volume LPS injected for the base case and two other realizations of the model. These realizations have different pore size distributions, however, are generated using the same statistical parameters such as minimum and maximum pore size, pore-throat length and coordination number. Therefore, the simulated residual oil saturation at the end of the imbibition process is different from one realization to another. As can be seen from the figure, injection of LPS reduces the residual oil in the base case approximately by $10 \%$. Similar trends can also be seen for the other realizations. This reduction is attributed to the diversion of flow in microscopic scale that diverts the flow towards the capillary-trapped oil and generates higher flow potential for the fluid displacement. Findings from the earlier works including both simulation (Bolandtaba et al. 2009) and experimental (Spildo et al. 2008) studies support this hypothesis.

It is of high importance to identify the LPS mechanism and its effect on how LPS contributes to oil mobilization. As we stated earlier, the concentration of LPS in brine is very low (typically less than $1,000 \mu \mathrm{g} / \mathrm{g}$ ). Hence, mechanisms that are highly sensitive to concentration seem to have the least effect. In addition, increase in solution viscosity by LPS and also reduction of area open to flow due to the polymer adsorption can contribute, but may not be the dominant processes for extra oil recovery. Since the average size of particles (typically between 100 and $300 \mathrm{~nm}$ ) is much smaller than that of pore elements ( $\mu \mathrm{m}$ scale), we also expect no straining happens during the LPS injection. Therefore, it is the log-jamming mechanism that is expected to deliver the highest impact on increasing the oil production efficiency. 


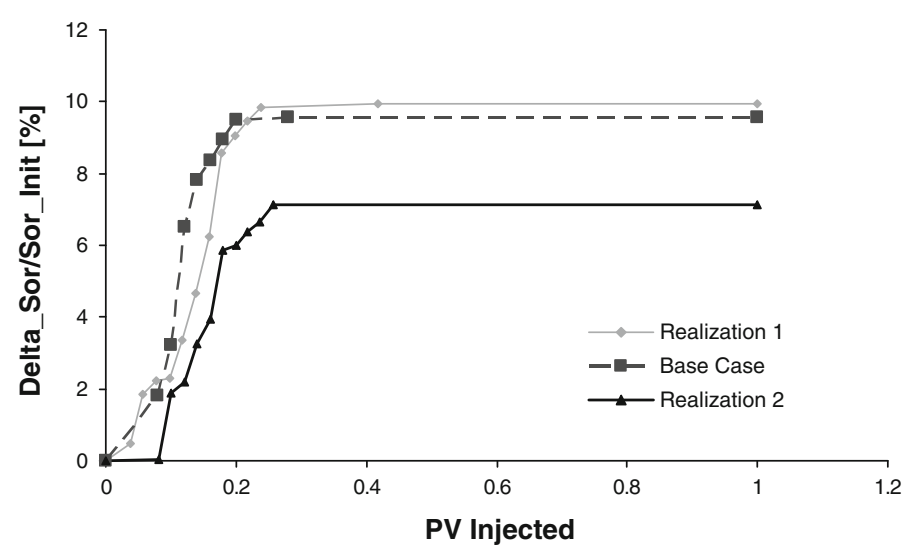

Fig. 11 Reduction of residual oil saturation during LPS injection for the base case and two more realizations

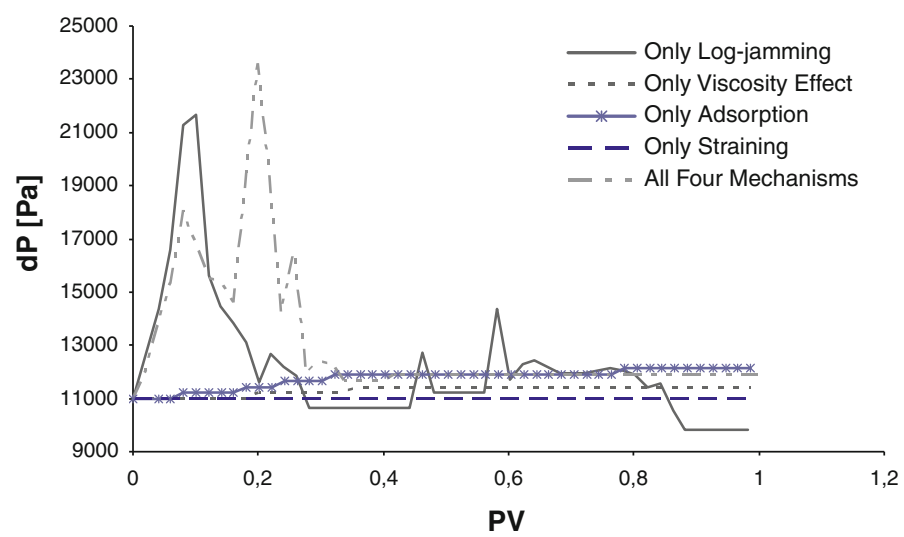

Fig. 12 The variation of pressure difference across the network as a function of PV LPS injected for different scenarios

The pressure drop across the network can be a good indicator that can be used to evaluate influence of each individual polymer mechanism. With the network properties given in Table 2, four simulation runs were performed on the base case (see Table 2 for the basic parameters of the model). In each run, only one mechanism is simulated and the effects of others are not included. Figure 12 gives the pressure drop during the LPS simulation as a function of pore volume injected. According to the graph, except the straining effect, the other mechanisms cause $\Delta P$ being increased. However, it is only log-jamming which causes the mobilization of trapped oil and leads to extra oil recovery. The other processes raises the pressure drop, however, such increase apparently is not alone enough to mobilize the oil. The result from other realizations of the network and also earlier results from network simulation (Bolandtaba et al. 2009) confirm our expectation. It should be noted that none of the pore channels are blocked by means of straining mechanism because the size of particles is much smaller than the pore elements.

It is important to note that even though the adsorption is marked as low-effective mechanism, it may facilitate blocking event by reducing the hydraulic radius of pore channels. This hypothesis has been tested by running two simulations. In the first case, we consider 
Table 3 Effect of adsorption mechanism on pore blocking and reduction of residual oil saturation

\begin{tabular}{lllll}
\hline Case name & Initial sor $(\%)$ & Final sor $(\%)$ & Sor reduction $(\%)$ & No. bond blocked \\
\hline All mechanisms & 38.55 & 35.80 & 7.13 & 1,037 \\
All except adsorption & 38.55 & 35.36 & 8.27 & 1,106 \\
\hline
\end{tabular}

Table 4 Fundamental properties of the network model used in this wettability sensitivity analysis

\begin{tabular}{lll}
\hline Parameter & Value & Unit \\
\hline Network size & $15 \times 15 \times 15$ & Node \\
Pore size & $2.4-20$ & $\mathrm{Mm}$ \\
Coordination number & 4.02 & - \\
Pore element length & $0.8-1.12$ & $\mathrm{Mm}$ \\
Porosity & 31.02 & $\%$ \\
Absolute permeability & 924 & $\mathrm{mD}$ \\
Interfacial tension & 41 & $\mathrm{mN} / \mathrm{m}$ \\
Largest water radius/smallest oil radius $\left(R_{\text {wet }}\right)$ & 15 & $\mathrm{Mm}$ \\
\hline
\end{tabular}

Table 5 Performance of LPS for different wettability conditions

\begin{tabular}{|c|c|c|c|c|c|c|}
\hline \multirow[t]{2}{*}{ Case } & \multicolumn{2}{|c|}{$\operatorname{Cos}(\theta)$} & \multicolumn{2}{|l|}{ Sor at the end of } & \multirow[t]{2}{*}{ Reduction } & \multirow[t]{2}{*}{$\%$ Improve } \\
\hline & Min & Max & Water injection & LPS injection & & \\
\hline 1 & 0.1 & 0.1 & 0.0850 & 0.0768 & 0.82 & 9.65 \\
\hline 2 & 0.1 & 0.3 & 0.1701 & 0.1392 & 3.08 & 18.13 \\
\hline 3 & 0.1 & 0.5 & 0.3252 & 0.2378 & 8.75 & 26.89 \\
\hline 4 & 0.1 & 0.7 & 0.3960 & 0.2998 & 9.63 & 24.31 \\
\hline 5 & 0.1 & 0.9 & 0.4264 & 0.3416 & 8.47 & 19.87 \\
\hline
\end{tabular}

the effect of all the mechanisms, while in the second case all the mechanisms except the adsorption are included. Table 3 shows the results.

As can be seen, the number of blocked bonds in the case with no adsorption is higher. Moreover, the residual oil is reduced more in the case without adsorption. This shows that there are cooperative effects between different mechanisms. Further, this behavior can be attributed to the fact that the adsorption mechanism removes LPS particles from the solution. Therefore, the concentration in the pore elements never reaches the critical concentration needed for pore blocking or would do so in later stages of the simulation. This result causes the number of pore channels that could potentially be blocked by polymer particles to be reduced. Such behavior has been shown in Fig. 13 where the distribution of blocked pore elements for the two cases has been described. As shown, the number of small pore channels that are blocked is larger in the case that does not consider the adsorption effect. This trend can be seen in the rest of the graph except the tail of the distribution that represents the blocking of larger pore elements. As can be seen, opposite events happens. Larger pore elements can only be blocked if we consider adsorption effects. This can be related to the cooperative effect between the entrapment mechanisms and the adsorption mechanism in which the hydraulic radius of larger pore elements are reduced by adsorption which facilitates the blocking event. 


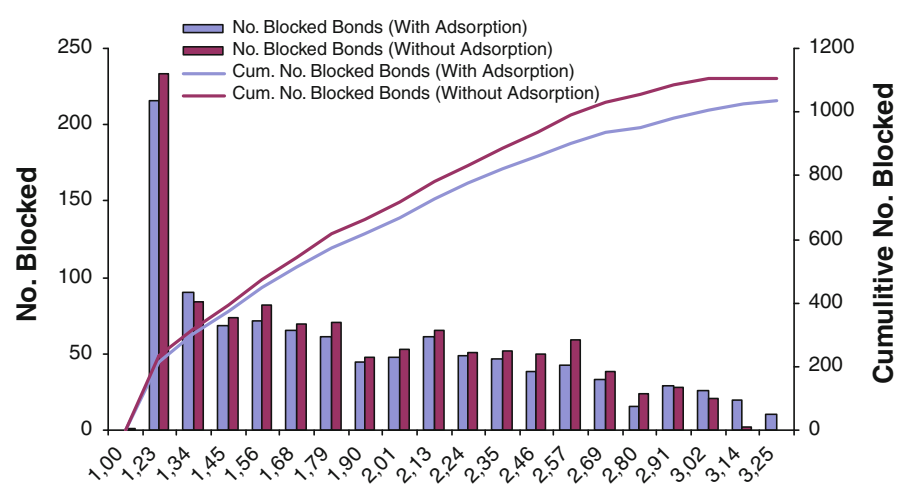

Pore Size [am]

Fig. 13 The effect of adsorption mechanism on distribution of blocked water bonds. The blue graph represents the case that includes adsorption while the red graph represents the case without the adsorption

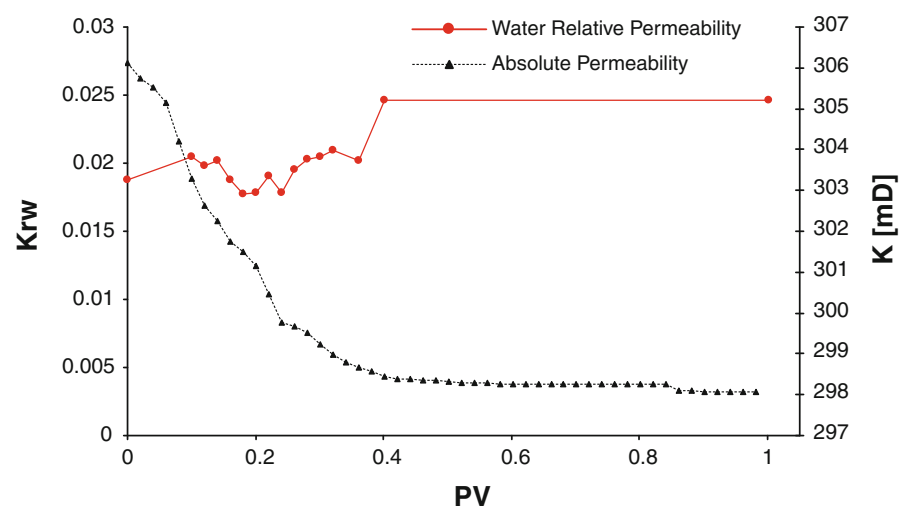

Fig. 14 Absolute permeability of the network and water relative permeability as a function of pore volume LPS injected

During LPS injection, the water relative permeability fluctuates. The blocking of pore channels caused by the log-jamming mechanism decreases the conductivity of the network and in particular reduces the water relative permeability. Moreover, the increase in water relative permeability is contributed to the additional network conductivity due to the extra room available to water phase after some oil is produced. Therefore, the water relative permeability is a balance between the amount of blocking and the amount of oil produced. Figure 14 shows the plot of relative permeability and also the absolute permeability of the network during the LPS injection process.

Conventional CDG injection focuses only on controlling the injection profile and improving the in-depth sweep. However, the new mechanisms associated to linked polymer solution attempts to improve the microscopic displacement efficiency in addition to the profile control. The concept of microscopic diversion due to log-jamming mechanism is illustrated in Fig. 15. Polymer molecules are heavier than those of water therefore their travel speed is less. When the LPS solution approaches a narrow pore channel, high speed water molecules pass the pore element and polymer molecules settle down on the entrance of the pore ele- 
(a)

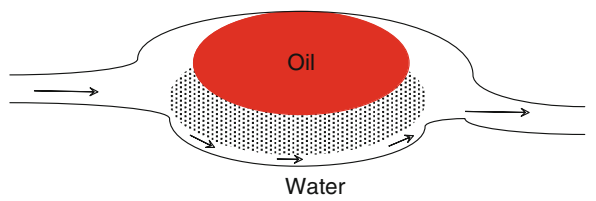

(b)

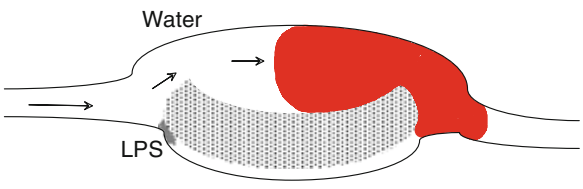

Fig. 15 Microscopic diversion concept shown schematically for LPS injection. a Water flows through narrow pore channels in the bottom while oil is trapped on larger pore element. b Slow blocking of LPS causes the flow diversion towards the trapped oil. If the viscous force is enough, oil can be mobilized

ment. As can be seen in Fig. 15, slow aggregation of LPS particles finally blocks the narrow pore channel, forcing the water flow to be diverted and this can in some cases divert the flow towards the trapped oil. This event changes the micro-scale pressure distribution and increases the local viscous forces and consequently leads to the oil mobilization. After flow diversion, the trapped oil comes in contact with injecting water resulting in an improvement in macroscopic sweep efficiency. In addition, the microscopic sweep efficiency improves because the disconnected oil is mobilized when the injecting fluid creates a pressure drop over the oil cluster. The way LPS influences fluid properties and topology of porous media introduces a new mechanism for fluids displacement and therefore is considered as a new EOR method.

\subsection{Wettability Sensitivity}

Reservoirs with high heterogeneity and low injection water salinity were reported as suitable candidates to perform LPS injection (Spildo et al. 2008). Several laboratory tests investigated the size of polymer particle, effect of brine salinity, temperature, and ratio of polymer to cross-linker, however, none of them addresses the effect of wettability on performance of injection.

The efficiency of LPS injection on different wettability conditions is investigated here by performing simulations with five cases. Each case is characterized by different distribution of intrinsic contact angles after ageing process. In order to generate different cases with different wettability conditions, we changed the maximum cosine of intrinsic contact angle in the pore-throats while the minimum cosine of intrinsic contact angle remained constant. Table 5 provides the simulations output and the reduction of residual oil saturation under different wettability conditions. Except for the wettability parameters, all the cases use the network properties given in Table 4. The wettability condition for each case can be visually determined by observing the imbibition capillary pressure curve (See Fig. 16). As can be seen, among these scenarios, case number 1 and 5 belong to the conditions which represent stronger oil-wet and water-wet environment, respectively, while case number 3 describes a mixed weakly water-wet condition.

As can be seen from data in Table 5 and the corresponding capillary pressure curve in Fig. 16, LPS efficiency on mobilizing the trapped oil increases as the medium becomes weakly water-wet. The highest residual oil reduction is seen for the case 3 which represents the weakest water wet condition. The advancing capillary entry pressure for most of the porethroats in this simulation case is close to zero. According to the double displacement criteria given by Eq. 10, both capillary forces and viscous forces contribute to the mobilization of trapped oil. Since the entry pressure for majority of the pore-throats is very low, a small 


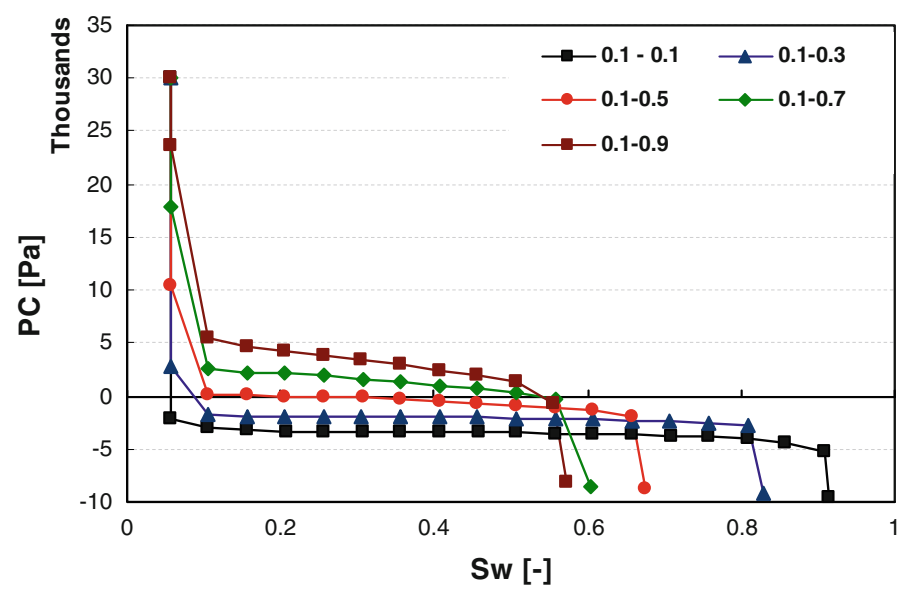

Fig. 16 The imbibition capillary pressure curve for the scenarios having different intrinsic contact angle distribution (note that the legend shows the cosine of contact angle)

change in pressure distribution in the network due to the LPS pore-blocking mechanisms can cause the pressure difference across the trapped bond being large enough to overcome the capillary forces. As a result, the disconnected oil can be moved. As the system becomes more oil wet or water wet, larger pressure difference is required to move the trapped oil and therefore, the recovery is less. However, this hypothesis needs to be treated with some caution since it is based on wettability variation alone, rather than considering a group of parameters (e.g., initial water saturation, wettability class, pore size distribution, etc.) that might interact with wettability condition.

\section{Summary and Conclusion}

A conceptual framework has been suggested to model several enhanced oil recovery methods for network model applications. Based on this framework, a 3D two-phase network model was developed.

The mobilization of capillary trapped oil in the network model application has been introduced by defining the criterion for double displacement of reservoir fluids at the pore scale. The effect of both capillary forces and viscous forces was included in the trapped oil displacement mechanism.

A new approach for modeling enhanced oil recovery methods has been suggested by coupling a quasi-static network model with a single-phase transport model in order to attain better estimation of fluid flow.

The methodology has been successfully applied to model the flow of colloidal dispersion gel and linked polymer solution. Several polymer mechanisms that are influential during CDG/LPS injection were described in detail. The mechanisms are viscosity effect, adsorption, straining, and log-jamming.

With the pore structure and LPS properties from earlier experimental work, the simulations showed that log-jamming mechanism is the dominant process. The microscopic diversion associated with flow diversion caused by the log-jamming effect leads to mobilization of capillary trapped oil. 
The efficiency of linked polymer solution on mobilizing residual oil has been studied under different wettability conditions. Results suggest that weakly wet reservoirs are the best candidates for performing linked polymer solution injection.

Acknowledgment The authors would like to acknowledge the PETROMAKS program at the Norwegian Research Council and Statoil for financial support to our EOR research.

Open Access This article is distributed under the terms of the Creative Commons Attribution Noncommercial License which permits any noncommercial use, distribution, and reproduction in any medium, provided the original author(s) and source are credited.

\section{References}

Aarra, M.G., Bjørsvik, M., Høiland, H., Skodvin, T., Skauge, A.: Linked polymer solutions for improved oil recovery by waterflooding. In: 13th European Symposium in Improved Oil Recovery. 25-27 April. SPE. Budapest, Hungary (2005)

Al-Gharbi, M.S., Blunt, M.J.: Dynamic network modelling of two-phase drainage in porous media. Phys. Rev. E 71, 016308 (2005)

Avraam, D.G., Payatakes, A.C.: Flow mechanisms, relative permeabilities and coupling effects in steady-state two-phase flow in porous media. The case of strong wettability. Ind. Eng. Chem. Res. 38, 778-786 (1999)

Berkowits, B., Balberg, I.: Percolation theory and its application to groundwater hydrology. Water Res. 29, 775-794 (1993)

Bjørsvik, M.: Physico-chemistry characterization of colloidal dispersion gels. PhD thesis, University of Bergen, Norway (2008)

Bjørsvik, M., Høiland, H., Skauge, A.: Formation of colloidal dispersion gels from aqueous polyacrylamide solutions. Colloids Surfaces A (2007). doi:10.1016/j.colsurfa.2007.11.025

Blunt, M., King, M.J., Scher, H.: Simulation and theory of two-phase flow in porous media. Phys. Rev. A 46(12), 7680-7699 (1992)

Blunt, M.J., Jackson, M.D., Piri, M., Valvatne, P.H.: Detailed physics, predictive capabilities and macroscopic consequences for pore-network models of multiphase flow. Adv. Water Resour. 25, 1069-1089 (2002)

Bolandtaba, S.F., Skauge, A., Mackay, E.: Pore-scale modeling of linked polymer solution (LPS)—a new EOR process. In: EAGE IOR Conference, Paris, 27-29 April (2009)

Broadbent, S.R., Hammersley, J.M.: Percolation processes, I and II. Proc. Camb. Philos. Soc. 53, 629-645 (1957)

Chang, H.L., Sui, X., Xiao, L., Guo, Z., Yao, Y., Xiao, Y., Chen, G., Song, K., Mack, J.C.: Successful field pilot of in-depth colloidal dispersion gel (CDG) technology in daqing oil field. SPE Res. Eval. Eng. 9(5), 664-673 (2006)

Chatzis, I., Dullien, F.A.L.: Modelling pore structures by 2-D and 3-D networks with application to sandstones. J. Can. Petrol. Technol. 16, 97-108 (1977)

Constantinides, G.N., Payatakes, A.C.: Network simulation of steady-state two-phase flow in consolidated porous media. AIChE J. 42, 369-382 (1996)

Dias, M.M., Payatakes, A.C.: Network models for two-phase flow in porous media. Part 1. Immiscible microdisplacement of non-wetting fluids. J. Fluid Mech. 164, 305-336 (1986a)

Dias, M.M., Payatakes, A.C.: Network models for two-phase flow in porous media. Part 2. Motion of oil ganglia. J. Fluid Mech. 164, 337-358 (1986b)

Dias, D., Somaruga, C., Norman, C., Romero, J.: Colloidal dispersion gels improve oil recovery in a heterogeneous Argentina waterflood. SPE 113320-MS-P. In: SPE/DOE Improved Oil Recovery Symposium, Tulsa, Oklahoma, USA, 19-23 April (2008)

Dixit, A.B., Mc Dougall, S.R., Sorbie, K.S., Buckley, J.S.: Pore-scale modeling of wettability effects and their influence on oil recovery. SPE Reserv. Eval. Eng. 2, 25-36 (1999)

Dominguez, J.G., Willhite, G.P.: Retention and flow characteristics of polymer solutions in porous media. Soc. Pet. Eng. J. April, 111-121 (1977)

Dong, H., Puhua, Y., Weili, L.Y., Qingxia, L., Shaozi, C., Zhengyu, S., Jinxing, T., Xiaolei.: Flow mechanism investigation and field practice for low concentration flowing gel. In: SPE 50929 SPE International Conference and Exhibition. Beijing, China 2-6 November (1998)

Fatt, I.: The network model of porous media. I. Capillary pressure characteristics. Trans. AIME 207, $144-159$ (1956a) 
Fatt, I.: The network model of porous media. II. Dynamic properties of a single size tube network. Trans. AIME 207, 160-163 (1956b)

Fatt, I.: The network model of porous media. III. Dynamic properties of networks with tube radius distribution. Trans. AIME 207, 164-181 (1956c)

Fenwick, D.H., Blunt, M.J.: Network modeling of three-phase flow in porous media. SPE J. 3, 86-97 (1998)

Flory, P.J.: Principles of Polymer Chemistry. Cornel University Press, Ithaca (1953)

Gunstensen, A.K., Rothman, D.H.: Lattice Boltzmann studies of immiscible two-phase flow through porous media. J. Geophys. Res. 98(B4), 6431-6441 (1993)

Heiba, A.A., Sahimi, M., Scriven, L.E., Davis, H.T.: Percolation theory of two-phase relative permeability. SPE Reserv. Eng. 7, 123-132 (1992)

Hou, J.: Network modeling of residual oil displacement after polymer flooding. J. Pet. Sci. Eng. 59(2007), 321-332 (2007)

Hughes, R.G., Blunt, M.J.: Pore-scale modeling of multiphase flow in fractures and matrix/fracture transfer. SPE J. 6(21), 26-36 (2001)

Huh, C., Lange, E.A., Cannella, W.J.: Polymer retention in porous media. SPE 20235. In: SPE/DOE Enhanced Oil Recovery Symposium. Tulsa, Oklahoma, USA, 22-25 (1990)

Jerauld, G.R., Salter, S.J.: Effect of pore-structure on hysteresis in relative permeability and capillary pressure: pore-level modeling. Transp. Porous Media 5, 103-151 (1990)

Joekar-niasar, S.M., Hassanizadeh, H.K., Dahle, H.K.: Non-equilibrium effects in capillarity and interfacial area in two-phase flow: dynamic pore-network modelling. J. Fluid Mech. (2010). doi:10.1017/ S0022112010000704

Koplik, J., Lasseter, T.J.: Two-phase flow in random network models of porous media. Soc. Petrol. Engng. J. 25, 89-100 (1985)

Kovscek, A.R., Wong, H., Radke, C.J.: Scenario for the development of mixed wettability in oil reservoirs. AIChE J. 39(6), 1072-1085 (1993)

Lenormand, R., Zarcone, C.: Role of roughness and edges during imbibition in square capillaries. In: 59th Annual Technical Conference and Exhibition of the Society of Petroleum Engineers of AIME, SPE 13264. Houston, Texas (1984)

Mack, J.C., Smith, J.E.: In-depth colloidal dispersion gels improve oil recovery efficiency. SPE/DOE 27780. In: SPE/DOE 9th Symposium on Improved Recovery. Tulsa, Oklahoma, 17-20 April (1994)

Mogensen, K., Stenby, E.H.: A dynamic two-phase pore-scale model for imbibition. Transp. Porous Media 32, 299-327 (1998)

Mohanty, K.K., Salter, S.J.: Multiphase flow in porous media pore level modeling. Paper SPE 11018. In: SPE Annual Technical Conference And Exhibition. New Orleans, Louisiana, 26-29 September (1982)

Morrow, N.R.: Effects of surface roughness on contact angle with special reference to petroleum recovery. J. Can. Pet. Technol. 14, 42-53 (1975)

Nguyen, V., Sheppard, A, Pinczewski, W, Knackstedt, M.: A dynamic network model for imbibition, Society of Petroleum Engineers International Petroleum Conference, Puebla, Mexico, November 9, SPE Paper Number 90365 (2004)

Øren, P.E., Bakke, S., Arntzen, O.J.: Extending predictive capabilities to network models. SPE J. 3, 324-336 (1998)

Osterloh, W.T., Law, E.J.: Polymer transport and rheological properties for polymer flooding in the North Sea Captain Field. SPE 39694. In: SPE/DOE Enhanced Oil Recovery Symposium, Tulsa, Oklahoma, USA, 19-22 April (1998)

Patzek, T.W.: Fundamentals of Multiphase Flow in Porous Media, 1st edn. Berkeley, U.C. Berkeley (1998)

Payatakes, A.C.: Dynamics of oil ganglia during immiscible displacement in water-wet porous media. Ann. Rev. Fluid Mech. 14, 365-393 (1982)

Porter, M.L., Schaap, M.G., Wildenschild, D.: Simulations of the capillary pressure-saturation-interfacial area relationship for porous media. Adv. Water Resour. 32(11), 1632-1640 (2009)

Ranganathan, R., Lewis, R., McCool, C.S., Green, D.W., Willhite, G.P.: Experimental study of the gelation behavior of a polyacrylamide/aluminum citrate colloidal-dispersion gel system. SPE J. December, 337-342 (1998)

Rocha, C.A., Green, D.W., Willhite, G.P., Michnick, M.J.: An experimental study of the interactions of aluminum citrate solutions and silica sand. SPE 18503. In: SPE International Symposium on Oilfield Chemistry. Houston, TX, February 8-10 (1989)

Ryazanov, A.V., van Dijke, M.I.J., Sorbie, K.S.: Two-phase pore-network modeling: existence of oil layers during water invasion. Transp. Porous Media 80, 79-99 (2009)

Sahimi, M.: And Transport in Porous Media and Fractured Rock-From Classical Methods to Modern Approaches. Weinheim, VCH (1995) 
Salter, S.J., Mohanty, K.K.: Multiphase flow in porous media: 1. Macroscopic observations and modeling. SPE 11017, Society of Petroleum Engineers. The paper was presented at the 57th Annual Fall Technical Conference and Exhibition of the Society of Petroleum Engineers, New Orleans, LA, Sept. 26-29.(1982)

Savins, J.: Non-Newtonian flow through porous media. Ind. Eng. Chem. 61(10), 18-47 (1969)

Shah, C.: Flow and immiscible displacement of power-law fluids and bingham plastics in porous media. $\mathrm{PhD}$ Thesis, University of Southern California, USA (1994)

Shiyi, Y., Dong, H., Qiang, W., Hua, Y.: Numerical simulator for the combination process of profile control and polymer flooding. SPE 64792. In: SPE International Oil and Gas Conference and Exhibition in China. Beijing, China, 7-10 November (2000)

Singh, M., Mohanty, K.K: Review: dynamic modeling of drainage through three-dimensional porous materials. Chem. Eng. Sci. 8, 1-18 (2003)

Skauge, A., Ottesen, B.: A summary of experimentally derived relative permeability and residual saturation on north sea reservoir cores. In: International Symposium of the SCA. Monterey, CA, September (2002)

Sorbie, K.S.: Polymer-Improved Oil Recovery. Blackie and Son, Bishopbriggs, Glasgow (1991)

Spildo, K., Skauge, A., Aarra, M.G., Tweheyo, M.T.: A new polymer application for north sea reservoirs. SPE 113460. In: SPE/DOE Improved Oil Recovery Symposium. Tulsa, Oklahoma, USA, 20-23 April 2008 (2008)

Szabo, M.T.: An evaluation of water-soluble polymers for secondary oil recovery-part 1 and 2. J. Pet. Technol. 31(5), 553-570 (1979)

Van der Marck, S.C., Matsuura, T., Glas, J.: Viscous and capillary pressures during drainage: network simulations and experiments. Phys. Rev. E 56, 5675-5687 (1997)

Valvatne, P.H., Blunt, M.J.: Predictive pore-scale modelling of two-phase flow in mixed wet media. Water Resour. Res. 40, W07406 (2004)

Valvatne, P., Piri, M., Lopez, X., Blunt, M.J.: Predictive pore-scale modeling of single and multiphase flow. Transp. Porous Media 55, 71-89 (2004)

Van Brakel, J.: Pore space models for transport phenomena in porous media: review and evaluation with special emphasis on capillary liquid transport. Powder Technol. 11, 205-236 (1975)

Van Kats, F.M., Egberts, P.J.P.: Simulation of three-phase displacement mechanisms using a 2D LatticeBoltzmann model. Transp. Porous Media 37(1), 55-68 (1999)

Wilkinson, D., Willemsen, J.F.: Invasion percolation: a new form of percolation theory. J. Phys. A 16, $3365-3376$ (1983) 